\title{
Review Article \\ Controversial Issues in Kyphoplasty and Vertebroplasty in Osteoporotic Vertebral Fractures
}

\author{
Ioannis D. Papanastassiou, ${ }^{1,2}$ Andreas Filis, ${ }^{1}$ Maria A. Gerochristou, ${ }^{3}$ and Frank D. Vrionis ${ }^{1}$ \\ ${ }^{1}$ H. Lee Moffitt Cancer Center \& Research Institute, Neuro-Oncology Program and Department of NeuroOncology and Orthopaedics, \\ University of South Florida College of Medicine, 12902 Magnolia Drive, Tampa, FL 33647, USA \\ ${ }^{2}$ General Oncological Hospital Kifisias "Agioi Anargyroi”, Athens, Greece \\ 3 "Andreas Syngros" Hospital, 16121 Athens, Greece
}

Correspondence should be addressed to Ioannis D. Papanastassiou; ioannis.papanastassiou@gmail.com

Received 28 October 2013; Accepted 17 January 2014; Published 4 March 2014

Academic Editor: Takashi Saku

Copyright (C) 2014 Ioannis D. Papanastassiou et al. This is an open access article distributed under the Creative Commons Attribution License, which permits unrestricted use, distribution, and reproduction in any medium, provided the original work is properly cited.

Kyphoplasty (KP) and vertebroplasty (VP) have been successfully employed for many years for the treatment of osteoporotic vertebral fractures. The purpose of this review is to resolve the controversial issues raised by the two randomized trials that claimed no difference between VP and SHAM procedure. In particular we compare nonsurgical management (NSM) and KP and VP, in terms of clinical parameters (pain, disability, quality of life, and new fractures), cost-effectiveness, radiological variables (kyphosis correction and vertebral height restoration), and VP versus KP for cement extravasation and complications profile. Cement types and optimal filling are analyzed and technological innovations are presented. Finally unipedicular/bipedicular techniques are compared. Conclusion. VP and KP are superior to NSM in clinical and radiological parameters and probably more cost-effective. $\mathrm{KP}$ is superior to VP in sagittal balance improvement and cement leaking. Complications are rare but serious adverse events have been described, so caution should be exerted. Unilateral procedures should be pursued whenever feasible. Upcoming randomized trials (CEEP, OSTEO-6, STIC-2, and VERTOS IV) will provide the missing link.

\section{Introduction}

Osteoporosis is considered to be amongst the 10 most important world diseases according to World Health Organization, leading to Vertebral Compression Fractures (VCFs) which dramatically increase morbidity and mortality [1-3]. Two randomized trials in the New England Journal of Medicine (NEJM) that showed no benefit from vertebroplasty (VP) over a simulated procedure $[4,5]$ may have contributed to the decline in utilization of Vertebral Augmentation Procedures (VAPs) and especially VP for treating VCFs in recent years $[6,7]$. However, the field is expanding and there seems to be a tremendous scientific interest in VAPs, resulting in more than 250 articles published annually on VP and kyphoplasty (KP). Many issues remain controversial and even scientific societies give contradicted recommendations with interventional radiologists praising and orthopedic surgeons condemning VP $[8,9]$.

In view of this controversy we published a meta-analysis on comparative prospective trials in 2012 [10]. In this updated review we try to give insight into many of the questions in this analysis: (1) what is the evidence on pain relief/Quality of Life (QoL) improvement for VAPs versus NSM, (2) are VAPs cost-effective, (3) does KP provide more kyphotic reduction than VP and does this have a clinical implication, (4) is cement leaking more with VP, (5) what is the risk for adjacent fractures, (6) complication profile of VAPs, (7) cement types, characteristics, and optimal filling, (8) unipedicular versus bipedicular approach, and (9) newer designs. 


\section{Pain Relief/Disability/QoL Improvement}

With the exception of the 2 NEJM RCTs and a smaller RCT that reported no benefit of VP versus SHAM $[4,5]$ or NSM $[11,12]$ the vast majority of prospective comparative studies (Tables 1 and 2) support the superiority of VAPs versus NSM [13-27], with only 1 newer study reporting better results from KP until the 1st postoperative month and then equivalence [28]. When comparing VP with KP, it seems that both procedures offer a 4-5 point average reduction from baseline (in a 10-point scale), so most authors believe that the threshold for performing the procedure is a preoperative Visual Analogue Scale (VAS) pain score of at least 4 or 5 [2940]. Few studies report better pain relief from KP up to 1-2 years postoperatively $[41,42]$. Patients in more severe pain seem to benefit most from the procedure [43].

In terms of disability/QoL improvement, the literature suggests that there may be an advantage of KP over VP and NSM [10]. Published studies either report equivalence of procedures $[29,30,32,34-40,46]$ or superiority of KP $[31,41,42]$. Since those parameters may better reflect the efficacy of the procedures compared to pain scales (i.e., VAS), they should be strictly scrutinized in future trials; indeed pain measurements frequently represent variations (pain with or without medications, positional/maximal/nocturnal/average pain, etc.) and not surprisingly even between RCTs there are striking differences (i.e., double size effect in VERTOS II [19] comparing with NEJM trials $[4,5])$.

\section{Are VAPs Cost-Effective? Mortality Reduction}

Edidin et al. published a retrospective study on a large Medicare population that showed reduced mortality, a $10 \%$ survival benefit in patients undergoing VAPs over NSM, with KP patients having 23\% reduced mortality relative risk comparing to VP [47]. Adjusted life expectancy was $85 \%$ greater for operated than nonoperated patients, while KP patients had a 34\% greater adjusted life expectancy than vertebroplasty patients [3]. Same results were published from another Medicare database; estimated three-year survival rates were $42.3 \%, 49.7 \%$, and $59.9 \%$ for NSM, VP, and KP, respectively. The adjusted risk of death was $20.0 \%$ lower for the KP than for the VP group. KP patients had the shortest hospital stay and the highest hospital charges [48]. Operated patients in Taiwan also reported fewer hospital readmissions [49]. A prospective study from UK reports reduced mortality and morbidity one year postoperatively [50]. Another UK study from Svedbom et al., regarding costeffectiveness analysis, claims that KP is more cost-effective than VP/NSM [51]. Although the hospital/operative room costs are higher with KP [52], the possible mortality reduction from KP may explain those results. However, in a recent study from McCullough et al., the authors state that these striking differences in mortality may be attributed to selection bias; after propensity score matching, VAPs have similar mortality rates with NSM [53], highlighting the need for prospective comparative trials with longer follow-up focusing on mortality as primary end-point.

\section{VAPs and Kyphotic Reduction/Vertebral Height Restoration}

One of the advantages of KP over VP [31-36, 39, 41, 42, 44, 54] or NSM [15-18, 25, 55] as suggested by most authorities is the potential for kyphosis reduction. Only 2 prospective comparative studies claim equivalence between procedures $[37,45]$, the second one being a nonballoon kyphoplasty. Reduction of kyphosis with KP varies from $3.7^{\circ}$ to $8^{\circ}$ (mean $4.8^{\circ}$ ) whereas with VP it ranges from $0.5^{\circ}$ to $3^{\circ}$ (mean $1.7^{\circ}$ ) [10]. While some surgeons view that postural reduction is the most critical factor determining kyphotic postprocedural correction [56-58], or claiming equivalent (or superior) results with nonballoon KPs [59, 60], other authors [61] as well as the extensive literature documentation with balloon KPs stresses the fact that balloon inflation also plays a role. Another important issue is whether this degree of kyphotic reduction correlates with clinical improvement. Theoretically, an improvement in spinal alignment and biomechanical behavior of the spine should reduce the flexion moments, relax the paraspinal muscles, and lead to more upright posture, reduced pain, and fewer subsequent fractures [10]. Many authors do not investigate or report this outcome, with others reporting positive [31, 41, 55] or no correlation $[18,32,35,62,63]$ between restoration of sagittal balance alignment and clinical parameters. Perhaps the strongest indication that reduction does matter is the lately published study from the FREE investigators, on the subset analysis of the radiological surgical parameters; the authors report that patients with higher kyphotic angulation correction had higher QoL improvement [55]. In addition, studies in patients with adult degenerative spinal deformity have shown a strong correlation between sagittal balance correction and surgical outcomes.

\section{Cement Extravasation}

The second advantage of KP over VP is the potential for less cement leaking, as shown by most studies [30, 32, 33, 35, 36, $38,39,41,45,54]$, whereas some authors found no difference $[29,37,40,42]$. Polymethylmethacrylate (PMMA) leakage as shown in meta-analysis ranges from $18.1 \%$ in KP to $41.1 \%$ in VP [10], with reported rates up to $72 \%$ in VP (VERTOS II) [19]. Extravasation rates vary significantly between operators as a result of different reporting techniques, modalities (i.e., Computed Tomography versus X-rays), fracture level, cement volume, or viscosity [10]. Besides from cavity creation in $\mathrm{KP}$ (either with balloon or curettes) that allows for low-pressure controlled cement filling, cement viscosity playsa pivotal role [64]; an increasing number of publications report reduced leaking rates with higher viscosity cements and specialized cement delivery equipment or cannulas (i.e., side-opening cannulas that allow for medialized cement injection $[65,66])$, even for VPs or nonballoon KPs $[59,60]$. 


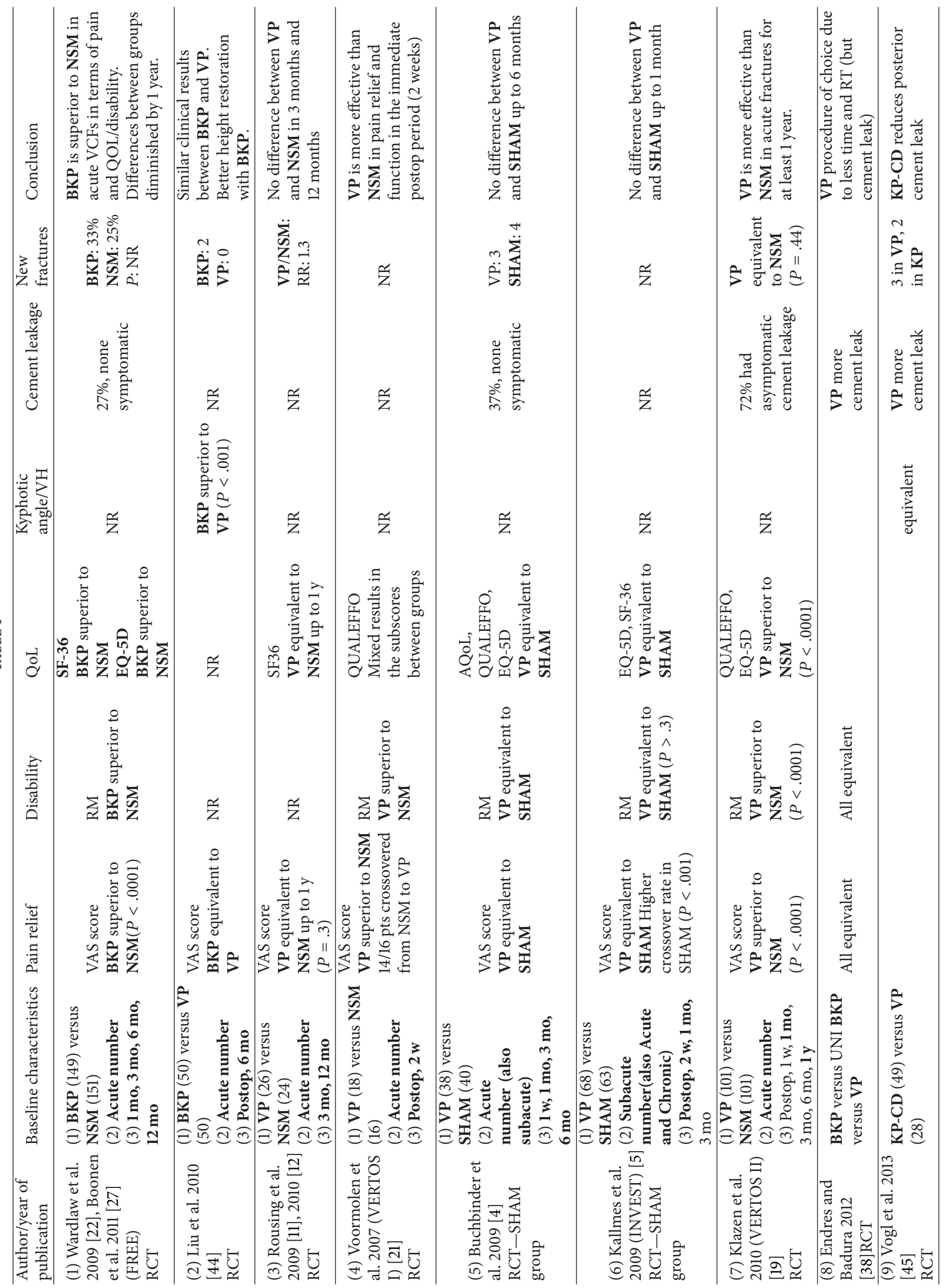




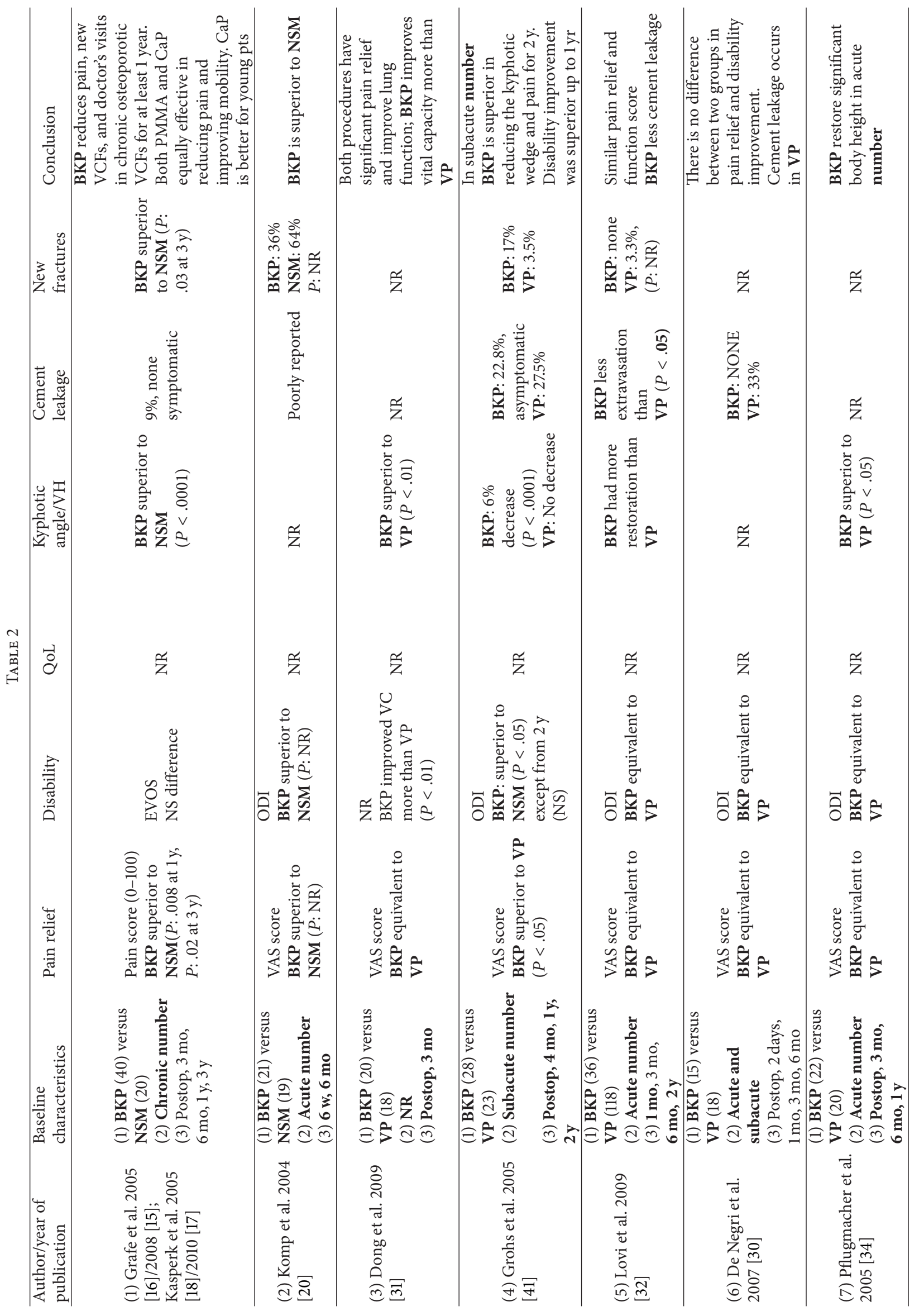




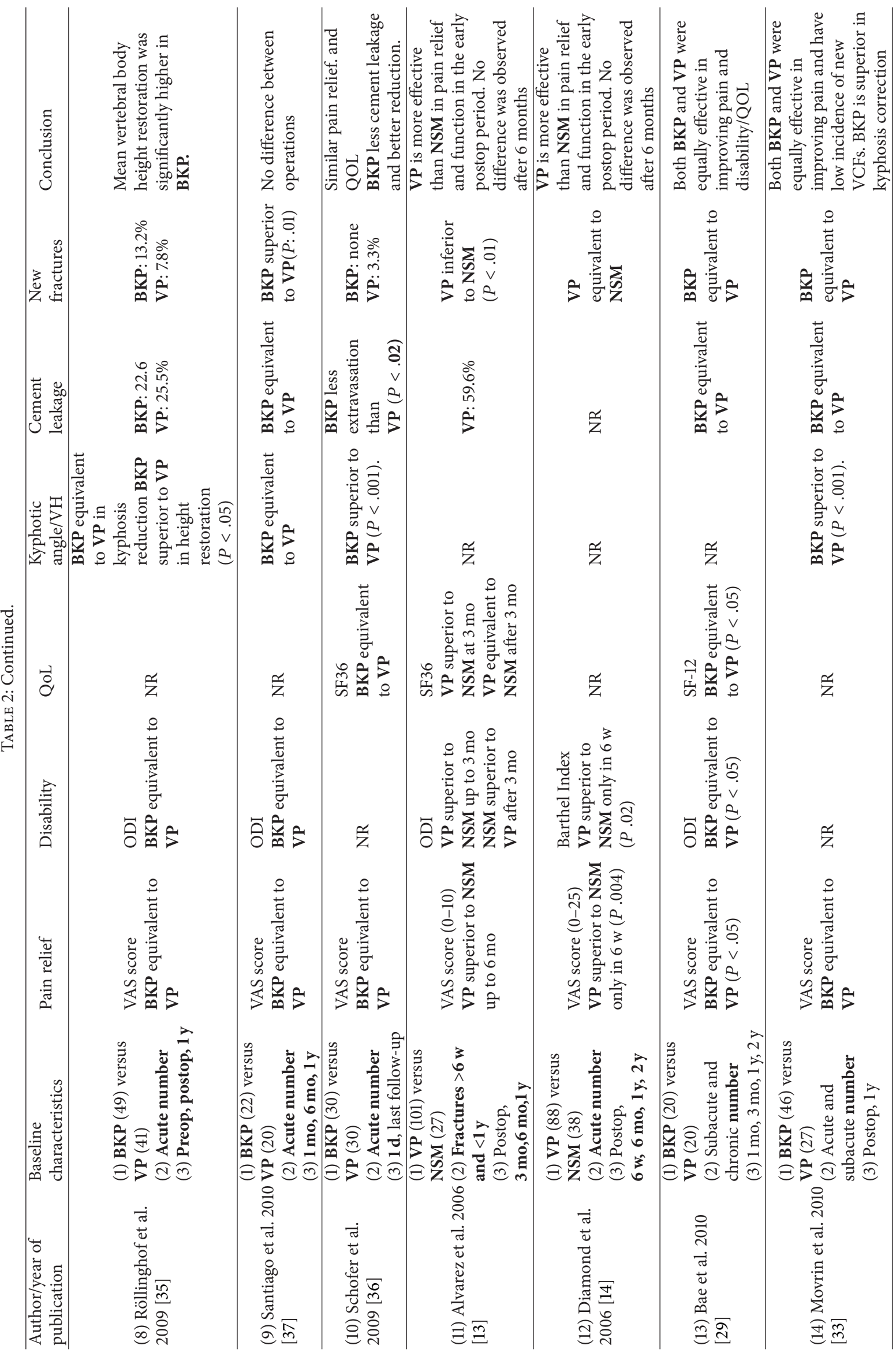




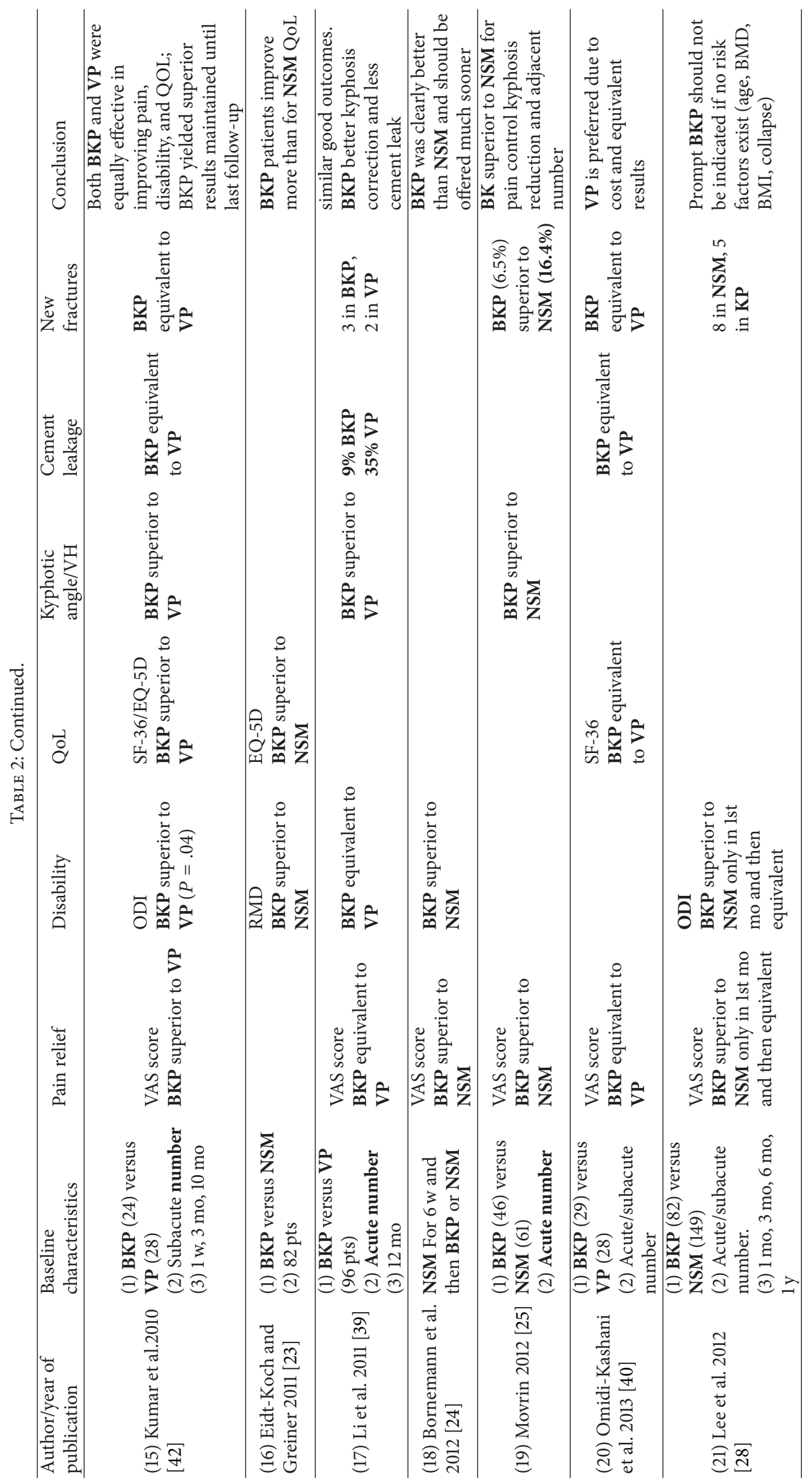




\section{Subsequent Fractures}

This is another controversial issue, with some authors proposing that the augmented vertebrae have a different modulus of elasticity/stiffness from the adjacent ones, posing larger forces in the surrounding vertebrae (stress-shielding phenomenon) [67], while others view cement interdigitation as a means of internal fixation and strengthening-restoration of the anterior column that leads to reduced flexion moment to the surrounding vertebral bodies [68]. Our study supports the 2nd notion with NSM leading to a double risk for future fractures $(22 \%)$ versus VAPs (11\%), with no difference between procedures [10]. Most prospective comparative published studies report reduced fractures with VAPs [15-18, 20, 22, 25], same rates $[4,14,19,28]$ or less fractures with NSM [13]. The most well recognized risk factor for adjacent fractures is cement leak into the disk space [69-72]; osteoporosis $[25,69,72]$ and kyphotic angle/degree of correction $[25,69]$ are also being implicated. In our practice, as suggested in the literature, to reduce the possibility of further fractures (especially when bony edema is found on the MRI at adjacent levels), we perform prophylactic augmentation $[73,74]$.

\section{Adverse Events}

VAPs are generally considered to be safe procedures but can result in rare serious complications [10] especially in the context of published trials from specialized centers $[4,5,19,22]$. However, with the widespread use of these minimal invasive operations from inexperienced surgeons, catastrophic failures and even deaths are being encountered. Cement has been found literally from top to bottom in the human body, including spinal foramen/canal [13, 32, 35], perivertebral segmental vessels [75], vena cava [76], foot (dorsalis pedis artery), heart $[77,78]$, and lungs $[77,79,80]$. Penetration of vital structures such as the aorta, pericardium (tamponade) [81], and lungs (pneumothorax) has been also encountered. Cardiovascular events such as desaturation on cement application or hypotension may happen in the operating theater, leading to fatalities in exceptional cases $[82,83]$. Pulmonary cement emboli is also frequent and may be encountered in up to one-fourth of patients undergoing VP (VERTOS II) [19], fortunately clinically silent in the vast majority of cases. Infection is a threatening complication, often necessitating corpectomy and cement removal and in a big case series it was calculated to have a $0.5 \%$ prevalence with $33 \%$ mortality [84]. We believe that with attention to detail and sufficient training, KP and VP are indeed low-risk procedures.

\section{Cement Types, Characteristics, and Optimal Filling}

PMMA has Young's Modulus (measure of stiffness) between 1,8 and $3,1 \mathrm{GPa}$, is more elastic than human bone $(14 \mathrm{GPa}$ for cortical bone), and, because of the stress shielding effect PMMA, might cause osteopenia [85].
In order to address these biomechanical disadvantages, bioactive/bioresorbable cements have been developed which show generally a higher bone affinity-index. Calcium phosphate cements (CPC) are divided into apatite CPCs and the less bioresorbable brushite CPCs and have in general lower mechanical properties than PMMA. Drawbacks of $\mathrm{CPC}$ are its lack of macroporosity so that fast bone ingrowth does not take place [85], low viscosity, and injectability of the material [86]. Calcium sulfate cements (CSC) have also been used in kyphoplasty. Perry et al. summarise that CSC are nontoxic, bioabsorbable, osteoconductive, and euthermic but have less stiffness than PMMA [87]. The latter is not necessarily disadvantageous since high stiffness may correlate with increased adjacent level fractures after kyphoplasty.

The volume of cement to be injected in order to achieve optimal results remains a point for debate among experts. Biomechanical studies suggest that small cement volumes ( $14 \%$ vertebrae filling or $3.5 \mathrm{cc}$ in L1) may be adequate to restore stiffness to predamaged levels [88], whereas Belkoff et al. and Molloy et al. report that bigger volumes $(16 \%-$ $30 \%$ ) are needed to restore vertebral strength and stiffness, respectively $[89,90]$. These conflicting results demonstrate that it may be difficult to extrapolate biomechanical data in clinical practice. Smaller amounts of cement $(3 \mathrm{cc}$ in thoracic and $6 \mathrm{cc}$ in lumbar) than those needed to restore the height of the vertebra may be enough to achieve resolution of clinical symptoms [91]. However, there is growing evidence that bigger cement volumes correlate with more pain resolution [43] and better restoration of sagittal alignment [57, 92] and in our practice we try to achieve maximum cement filling in a safe manner.

\section{Timing of Procedure}

This is another controversial issue, since early intervention in hyperacute fractures (less than 2-3 weeks) may lead to unnecessary surgery [11], whereas late intervention (after 23 months) may compromise results $[4,5,21,41]$ and leave patients in recumbence and agonizing pain. Most authorities advocate a trial of 2-6 weeks trial of conservative treatment before resorting to vertebral augmentation $[15,24,28,35$, 93]. Our data also indicate that after 7 weeks, clinical outcome is suboptimal and therefore surgery should not be further delayed [94]. Patients that are deemed to have a worse natural course include those suffering from burst or significant collapsed fractures [21, 28, 43], thoracic (or especially thoracolumbar [43]) location [95]. If those risk factors exist, an acute intervention is justified. In summary, in low-risk fractures we would opt for NSM (for 3-6 weeks approximately) and resort to augmentation should pain persists or deformity deteriorates, whereas in higher risk fractures (or intolerable pain) we would operate early [94].

\section{Unipedicular versus Bipedicular Approach}

Pros and cons of the unipedicular approach include less operative time/exposure to radiation and reduced cost versus probable suboptimal kyphotic reduction. However, both 
biomechanical data [96-98] and clinical series [99-102] suggest that unipedicular procedure is safe and effective. Comparative studies also claim no difference in clinical or radiological parameters [103-106] with the exception of a retrospective study by Chung and coauthors who found same pain reduction but superior kyphosis restoration with bipedicular approach [107]. Only difference may be the smaller cement amount filling in unilateral operations [103, 104], which may be as low as $0.8 \mathrm{cc}$ as seen from our data. Overall, there is no evidence to support superiority of bipedicular VAPs and unipedicular approach should be pursued whenever technically feasible [108]. A bipedicular approach is especially indicated in more severe cases of vertebral body collapse as this typically involves the midportion of the vertebral body, leaving the lateral portions accessible to vertebral augmentation.

\section{Newer Designs}

In balloon KP the inflatable bone tamp is designed to create a cavity where the cement is injected. Various such sets have been developed: Kyphon (Medtronic Inc.), Spasy (Joimax Inc.), AVAmax (Carefusion Inc.), and Ky/Spine (Ackermann Inc.).

In radiofrequency-targeted vertebral augmentation (RVTVA) the Stabilit system (Dfine Inc.) is utilised via a unipedicular approach and a specialized curved curette. Using radiofrequency activation, an ultrahigh-viscosity cement is prepared and then injected through a cement delivery instrument, in a slow, constant pace, minimizing cement leaking and ensuring uniform cement distribution, in a VP-like manner. Though relatively new, this technique might be superior to balloon kyphoplasty in terms of cement extrusion rates and trabecular bone destruction $[59,60,109]$.

The KIVA System (Benvenue Medical Inc.) is a novel kyphoplasty technique where a percutaneously introduced nitinol Osteo Coil guidewire is advanced through a deployment cannula and subsequently a PEEK Implant is implanted incrementally and fully coiled in the vertebral body. The system is subject to the currently running KAST clinical trial. Nonetheless, preliminary results show less amount of cement needed to be injected and lower extravasation rates in comparison to balloon KP [110].

\section{Future Perspective}

Evolution in hardware design and cement properties enables the operator to do the procedure faster and more safely. Unipedicular approach is gaining popularity when feasible, especially with the use of curved curettes; ultrahigh viscous cement, with specialized delivery equipment allow for uniform, controlled, low pressure cement filling. In spite of the early termination of the KAVIAR study due to small patient enrollment, other important RCTs are being anxiously anticipated [CEEP study (KP versus VP), OSTEO-6 (KP versus VP versus NSM), STIC2 (KP versus VP), and VERTOS IV (VP versus SHAM)] that will shed light into the controversial issues highlighted in this review.

\section{Conflict of Interests}

The authors declare that there is no conflict of interests regarding the publication of this paper.

\section{References}

[1] R. V. Chandra, A. J. Yoo, and J. A. Hirsch, "Vertebral augmentation: update on safety, efficacy, cost effectiveness and increased survival?” Pain Physician, vol. 16, no. 4, pp. 309-320, 2013.

[2] D. M. Kado, T. Duong, K. L. Stone et al., "Incident vertebral fractures and mortality in older women: a prospective study," Osteoporosis International, vol. 14, no. 7, pp. 589-594, 2003.

[3] A. A. Edidin, K. L. Ong, E. Lau, and S. M. Kurtz, "Life expectancy following diagnosis of a vertebral compression fracture," Osteoporosis International, vol. 24, no. 2, pp. 451-458, 2013.

[4] R. Buchbinder, R. H. Osborne, P. R. Ebeling et al., "A randomized trial of vertebroplasty for painful osteoporotic vertebral fractures," The New England Journal of Medicine, vol. 361, no. 6, pp. 557-568, 2009.

[5] D. F. Kallmes, B. A. Comstock, P. J. Heagerty et al., "A randomized trial of vertebroplasty for osteoporotic spinal fractures," The New England Journal of Medicine, vol. 361, no. 6, pp. 569-579, 2009.

[6] S. S. Long, W. B. Morrison, and L. Parker, "Vertebroplasty and kyphoplasty in the United States: provider distribution and guidance method, 2001-2010," American Journal of Roentgenology, vol. 199, no. 6, pp. 1358-1364, 2012.

[7] L. Manchikanti, V. Pampati, and J. A. Hirsch, "Analysis of utilization patterns of vertebroplasty and kyphoplasty in the Medicare population," Journal of NeuroInterventional Surgery, vol. 5, no. 5, pp. 467-472, 2013.

[8] American College of Radiology, "ACR-ASNR-ASSR-SIR-SNIS Practice guideline for the performance of vertebral augmentation," ACR Practice Guideline, 2012, http://www.acr.org/ / media/0AB72B20B91D4571A262BE946E889DC3.pdf.

[9] S. I. Esses, R. McGuire, J. Jenkins et al., "The treatment of symptomatic osteoporotic spinal compression fractures," Journal of the American Academy of Orthopaedic Surgeons, vol. 19, no. 3, pp. 176-182, 2011.

[10] I. D. Papanastassiou, F. M. Phillips, J. Van Meirhaeghe et al., "Comparing effects of kyphoplasty, vertebroplasty, and nonsurgical management in a systematic review of randomized and non-randomized controlled studies," European Spine Journal, vol. 21, no. 9, pp. 1826-1843, 2012.

[11] R. Rousing, M. O. Andersen, S. M. Jespersen, K. Thomsen, and J. Lauritsen, "Percutaneous vertebroplasty compared to conservative treatment in patients with painful acute or subacute osteoporotic vertebral fractures: three-months follow-up in a clinical randomized study," Spine, vol. 34, no. 13, pp. 1349-1354, 2009.

[12] R. Rousing, K. L. Hansen, M. O. Andersen, S. M. Jespersen, K. Thomsen, and J. M. Lauritsen, "Twelve-months followup in forty-nine patients with acute/semiacute osteoporotic vertebral fractures treated conservatively or with percutaneous vertebroplasty: a clinical randomized study," Spine, vol. 35, no. 5, pp. 478-482, 2010.

[13] L. Alvarez, M. Alcaraz, A. Perez-Higueras et al., "Percutaneous vertebroplasty: functional improvement in patients with osteoporotic compression fractures," Spine, vol. 31, no. 10, pp. 11131118, 2006. 
[14] T. H. Diamond, C. Bryant, L. Browne, and W. A. Clark, "Clinical outcomes after acute osteoporotic vertebral fractures: a 2-year non-randomised trial comparing percutaneous vertebroplasty with conservative therapy," Medical Journal of Australia, vol. 184, no. 3, pp. 113-117, 2006.

[15] I. A. Grafe, M. Baier, G. Nöldge et al., "Calcium-phosphate and polymethylmethacrylate cement in long-term outcome after kyphoplasty of painful osteoporotic vertebral fractures," Spine, vol. 33, no. 11, pp. 1284-1290, 2008.

[16] I. A. Grafe, K. Da Fonseca, J. Hillmeier et al., "Reduction of pain and fracture incidence after kyphoplasty: 1-Year outcomes of a prospective controlled trial of patients with primary osteoporosis," Osteoporosis International, vol. 16, no. 12, pp. 2005-2012, 2005.

[17] C. Kasperk, I. A. Grafe, S. Schmitt et al., "Three-year outcomes after kyphoplasty in patients with osteoporosis with painful vertebral fractures," Journal of Vascular and Interventional Radiology, vol. 21, no. 5, pp. 701-709, 2010.

[18] C. Kasperk, J. Hillmeier, G. Nöldge et al., "Treatment of painful vertebral fractures by kyphoplasty in patients with primary osteoporosis: a prospective nonrandomized controlled study," Journal of Bone and Mineral Research, vol. 20, no. 4, pp. 604612, 2005.

[19] C. A. H. Klazen, P. N. M. Lohle, J. De Vries et al., "Vertebroplasty versus conservative treatment in acute osteoporotic vertebral compression fractures (Vertos II): an open-label randomised trial," The Lancet, vol. 376, no. 9746, pp. 1085-1092, 2010.

[20] M. Komp, S. Ruetten, and G. Godolias, "Minimally invasive therapy for functionally unstable osteoporotic vertebral fracture by means of kyphoplasty: prospective comparative study of 19 surgically and 17 conservatively treated patients," Journal für Mineralstoffwechsel, vol. 11, supplement 1, pp. 13-15, 2004.

[21] M. H. J. Voormolen, W. P. T. M. Mali, P. N. M. Lohle et al., "Percutaneous vertebroplasty compared with optimal pain medication treatment: short-term clinical outcome of patients with subacute or chronic painful osteoporotic vertebral compression fractures. The VERTOS study," American Journal of Neuroradiology, vol. 28, no. 3, pp. 555-560, 2007.

[22] D. Wardlaw, S. R. Cummings, J. Van Meirhaeghe et al., "Efficacy and safety of balloon kyphoplasty compared with non-surgical care for vertebral compression fracture (FREE): a randomised controlled trial," The Lancet, vol. 373, no. 9668, pp. 1016-1024, 2009.

[23] D. Eidt-Koch and W. Greiner, "Quality of life results of balloon kyphoplasty versus non surgical management for osteoporotic vertebral fractures in Germany," Health Economics Review, vol. 1, no. 1, article 7, 2011.

[24] R. Bornemann, M. Hanna, K. Kabir, H. Goost, D. C. Wirtz, and R. Pflugmacher, "Continuing conservative care versus crossover to radiofrequency kyphoplasty: a comparative effectiveness study on the treatment of vertebral body fractures," European Spine Journal, vol. 21, no. 5, pp. 930-936, 2012.

[25] I. Movrin, "Adjacent level fracture after osteoporotic vertebral compression fracture: a nonrandomized prospective study comparing balloon kyphoplasty with conservative therapy," Wiener Klinische Wochenschrift, vol. 124, no. 9-10, pp. 304-311, 2012.

[26] D. Wardlaw, J. Van Meirhaeghe, J. Ranstam, L. Bastian, and S. Boonen, "Balloon kyphoplasty in patients with osteoporotic vertebral compression fractures," Expert Review of Medical Devices, vol. 9, no. 4, pp. 423-436, 2012.
[27] S. Boonen, J. Van Meirhaeghe, L. Bastian et al., "Balloon kyphoplasty for the treatment of acute vertebral compression fractures: 2-year results from a randomized trial," Journal of Bone and Mineral Research, vol. 26, no. 7, pp. 1627-1637, 2011.

[28] H. M. Lee, S. Y. Park, S. H. Lee, S. W. Suh, and J. Y. Hong, "Comparative analysis of clinical outcomes in patients with osteoporotic vertebral compression fractures (OVCFs): conservative treatment versus balloon kyphoplasty," The Spine Journal, vol. 12, no. 11, pp. 998-1005, 2012.

[29] H. Bae, M. Shen, P. Maurer et al., "Clinical experience using cortoss for treating vertebral compression fractures with vertebroplasty and kyphoplasty: twenty four-month follow-up," Spine, vol. 35, no. 20, pp. E1030-E1036, 2010.

[30] P. De Negri, T. Tirri, G. Paternoster, and P. Modano, "Treatment of painful osteoporotic or traumatic vertebral compression fractures by percutaneous vertebral augmentation procedures: a nonrandomized comparison between vertebroplasty and kyphoplasty," Clinical Journal of Pain, vol. 23, no. 5, pp. 425-430, 2007.

[31] R. Dong, L. Chen, Y. Gu et al., "Improvement in respiratory function after vertebroplasty and kyphoplasty," International Orthopaedics, vol. 33, no. 6, pp. 1689-1694, 2009.

[32] A. Lovi, M. Teli, A. Ortolina, F. Costa, M. Fornari, and M. Brayda-Bruno, "Vertebroplasty and kyphoplasty: complementary techniques for the treatment of painful osteoporotic vertebral compression fractures. A prospective non-randomised study on 154 patients," European Spine Journal, vol. 18, supplement 1, pp. S95-S101, 2009.

[33] I. Movrin, R. Vengust, and R. Komadina, "Adjacent vertebral fractures after percutaneous vertebral augmentation of osteoporotic vertebral compression fracture: a comparison of balloon kyphoplasty and vertebroplasty," Archives of Orthopaedic and Trauma Surgery, vol. 130, no. 9, pp. 1157-1166, 2010.

[34] R. Pflugmacher, F. Kandziora, R. Schröder et al., "Vertebroplasty and kyphoplasty in osteoporotic fractures of vertebral bodiesa prospective 1-year follow-up analysis," RoFo, vol. 177, no. 12, pp. 1670-1676, 2005.

[35] M. Röllinghoff, J. Siewe, K. Zarghooni et al., "Effectiveness, security and height restoration on fresh compression fractures a comparative prospective study of vertebroplasty and kyphoplasty," Minimally Invasive Neurosurgery, vol. 52, no. 5-6, pp. 233-237, 2009.

[36] M. D. Schofer, T. Efe, N. Timmesfeld, H.-R. Kortmann, and M. Quante, "Comparison of kyphoplasty and vertebroplasty in the treatment of fresh vertebral compression fractures," Archives of Orthopaedic and Trauma Surgery, vol. 129, no. 10, pp. 1391-1399, 2009.

[37] F. R. Santiago, A. P. Abela, L. G. Álvarez, R. M. Á. Osuna, and M. Del Mar Castellano García, "Pain and functional outcome after vertebroplasty and kyphoplasty. A comparative study," European Journal of Radiology, vol. 75, no. 2, pp. e108-e113, 2010.

[38] S. Endres and A. Badura, "Shield kyphoplasty through a unipedicular approach compared to vertebroplasty and balloon kyphoplasty in osteoporotic thoracolumbar fracture: a prospective randomized study," Orthopaedics and Traumatology, vol. 98, no. 3, pp. 334-340, 2012.

[39] X. Li, H. Yang, T. Tang, Z. Qian, L. Chen, and Z. Zhang, "Comparison of kyphoplasty and vertebroplasty for treatment of painful osteoporotic vertebral compression fractures: twelvemonth follow-up in a prospective nonrandomized comparative study," Journal of Spinal Disorders \& Techniques, 2011. 
[40] F. Omidi-Kashani, F. Samini, E. G. Hasankhani, A. R. Kachooei, K. Z. Toosi, and F. Golhasani-Keshtan, "Does percutaneous kyphoplasty have better functional outcome than vertebroplasty in single level osteoporotic compression fractures? A comparative prospective study," Journal of Osteoporosis, vol. 2013, Article ID 690329, 5 pages, 2013.

[41] J. G. Grohs, M. Matzner, K. Trieb, and P. Krepler, "Minimal invasive stabilization of osteoporotic vertebral fractures: a prospective nonrondomized comparison of vertebroplasty and balloon kyphoplasty," Journal of Spinal Disorders and Techniques, vol. 18, no. 3, pp. 238-242, 2005.

[42] K. Kumar, R. Nguyen, and S. Bishop, "A comparative analysis of the results of vertebroplasty and kyphoplasty in osteoporotic vertebral compression fractures," Neurosurgery, vol. 67, supplement 3, pp. 171-188, 2010.

[43] C. Roder, B. Boszczyk, G. Perler, E. Aghayev, F. Kulling, and G. Maestretti, "Cement volume is the most important modifiable predictor for pain relief in BKP: results from SWISSspine, a nationwide registry," European Spine Journal, vol. 22, no. 10, pp. 2241-2248, 2013.

[44] J. T. Liu, W. J. Liao, W. C. Tan et al., "Balloon kyphoplasty versus vertebroplasty for treatment of osteoporotic vertebral compression fracture: a prospective, comparative, and randomized clinical study," Osteoporosis International, vol. 21, no. 2, pp. 359-364, 2010.

[45] T. J. Vogl, R. Pflugmacher, J. Hierholzer et al., "Cement directed kyphoplasty reduces cement leakage as compared with vertebroplasty: results of a controlled, randomized trial," Spine, vol. 38, no. 20, pp. 1730-1736, 2013.

[46] M. Shen, H. Wang, G. Chen et al., "Factors affecting kyphotic angle reduction in osteoporotic vertebral compression fractures with kyphoplasty," Orthopedics, vol. 36, no. 4, pp. e509-e514, 2013.

[47] A. A. Edidin, K. L. Ong, E. Lau, and S. M. Kurtz, "Mortality risk for operated and nonoperated vertebral fracture patients in the medicare population," Journal of Bone and Mineral Research, vol. 26, no. 7, pp. 1617-1626, 2011.

[48] A. T. Chen, D. B. Cohen, and R. L. Skolasky, "Impact of nonoperative treatment, vertebroplasty, and kyphoplasty on survival and morbidity after vertebral compression fracture in the medicare population," The Journal of Bone \& Joint Surgery, vol. 95, no. 19, pp. 1729-1736, 2013.

[49] Y. W. Tsai, F. Y. Hsiao, Y. W. Wen et al., "Clinical outcomes of vertebroplasty or kyphoplasty for patients with vertebral compression fractures: a nationwide cohort study," Journal of the American Medical Directors Association, vol. 14, no. 1, pp. 41-47, 2013.

[50] Z. Klezl, N. Bhangoo, J. Phillips, G. Swamy, D. Calthorpe, and R. Bommireddy, "Social implications of balloon kyphoplasty: prospective study from a single UK centre," European Spine Journal, vol. 21, no. 9, pp. 1880-1886, 2012.

[51] A. Svedbom, L. Alvares, C. Cooper, D. Marsh, and O. Strom, "Balloon kyphoplasty compared to vertebroplasty and nonsurgical management in patients hospitalised with acute osteoporotic vertebral compression fracture: a UK cost-effectiveness analysis," Osteoporosis International, vol. 24, no. 1, pp. 355-367, 2013.

[52] A. K. Mehio, J. H. Lerner, L. M. Engelhart et al., "Comparative hospital economics and patient presentation: vertebroplasty and kyphoplasty for the treatment of vertebral compression fracture," American Journal of Neuroradiology, vol. 32, no. 7, pp. 1290-1294, 2011.
[53] B. J. McCullough, B. A. Comstock, R. A. Deyo, W. Kreuter, and J. G. Jarvik, "Major medical outcomes with spinal augmentation vs conservative therapy," JAMA Internal Medicine, vol. 173, no. 16, pp. 1514-1521, 2013.

[54] D. Xing, J. X. Ma, X. L. Ma et al., "A meta-analysis of balloon kyphoplasty compared to percutaneous vertebroplasty for treating osteoporotic vertebral compression fractures," Journal of Clinical Neuroscience, vol. 20, no. 6, pp. 795-803, 2013.

[55] J. Ranstam, A. Turkiewicz, S. Boonen, J. Van Meirhaeghe, L. Bastian, and D. Wardlaw, "Alternative analyses for handling incomplete follow-up in the intention-to-treat analysis: the randomized controlled trial of balloon kyphoplasty versus nonsurgical care for vertebral compression fracture (FREE)," BMC Medical Research Methodology, vol. 12, article 35, 2012.

[56] K. Yokoyama, M. Kawanishi, M. Yamada et al., "In not only vertebroplasty but also kyphoplasty, the resolution of vertebral deformities depends on vertebral mobility," American Journal of Neuroradiology, vol. 34, no. 7, pp. 1474-1478, 2013.

[57] C. Xu, H. X. Liu, and H. Z. Xu, "Analysis of related factors on the deformity correction of balloon kyphoplasty," American Journal of Neuroradiology, vol. 35, no. 1, pp. 202-206, 2014.

[58] D. T. Cawley, P. Sexton, T. Murphy, and J. P. McCabe, “Optimal patient positioning for ligamentotaxis during balloon kyphoplasty of the thoracolumbar and lumbar spine," Journal of Clinical Neuroscience, vol. 18, no. 6, pp. 834-836, 2011.

[59] R. Pflugmacher, R. Bornemann, E. M. Koch et al., "Comparison of clinical and radiological data in the treatment of patients with osteoporotic vertebral compression fractures using radiofrequency kyphoplasty or balloon kyphoplasty," Zeitschrift für Orthopädie und Unfallchirurgie, vol. 150, no. 1, pp. 56-61, 2012.

[60] B. A. Georgy, "Comparison between radiofrequency targeted vertebral augmentation and balloon kyphoplasty in the treatment of vertebral compression fractures: addressing factors that affect cement extravasation and distribution," Pain Physician, vol. 16, no. 5, pp. E513-E518, 2013.

[61] M. K. Shindle, M. J. Gardner, J. Koob, S. Bukata, J. A. Cabin, and J. M. Lane, "Vertebral height restoration in osteoporotic compression fractures: kyphoplasty balloon tamp is superior to postural correction alone," Osteoporosis International, vol. 17, no. 12, pp. 1815-1819, 2006.

[62] U. Berlemann, T. Franz, R. Orler, and P. F. Heini, "Kyphoplasty for treatment of osteoporotic vertebral fractures: a prospective non-randomized study," European Spine Journal, vol. 13, no. 6, pp. 496-501, 2004.

[63] R. Dong, L. Chen, T. Tang et al., "Pain reduction following vertebroplasty and kyphoplasty," International Orthopaedics, vol. 37, no. 1, pp. 83-87, 2013.

[64] M. Bohner, B. Gasser, G. Baroud, and P. Heini, "Theoretical and experimental model to describe the injection of a polymethylmethacrylate cement into a porous structure," Biomaterials, vol. 24, no. 16, pp. 2721-2730, 2003.

[65] P. F. Heini and C. Dain Allred, "The use of a side-opening injection cannula in vertebroplasty: a technical note," Spine, vol. 27, no. 1, pp. 105-109, 2002.

[66] N. Figueiredo, R. Rotta, A. Cavicchioli, D. Gonsales, and L. A. Casulari, "Kyphoplasty versus percutaneous vertebroplasty using the traditional and the new side-opening cannula for osteoporotic vertebral fracture," Journal of Neurosurgical Sciences, vol. 55, no. 4, pp. 365-370, 2011.

[67] U. Berlemann, S. J. Ferguson, L.-P. Nolte, and P. F. Heini, "Adjacent vertebral failure after vertebroplasty," Journal of Bone and Joint Surgery B, vol. 84, no. 5, pp. 748-752, 2002. 
[68] H. A. Yuan, C. W. Brown, and F. M. Phillips, "Osteoporotic spinal deformity: a biomechanical rationale for the clinical consequences and treatment of vertebral body compression fractures," Journal of Spinal Disorders and Techniques, vol. 17, no. 3, pp. 236-242, 2004.

[69] X. Ma, D. Xing, J. Ma et al., "Risk factors for new vertebral compression fractures after percutaneous vertebroplasty: qualitative evidence synthesized from a systematic review," Spine, 2013.

[70] E. P. Lin, S. Ekholm, A. Hiwatashi, and P.-L. Westesson, "Vertebroplasty: cement leakage into the disc increases the risk of new fracture of adjacent vertebral body," American Journal of Neuroradiology, vol. 25, no. 2, pp. 175-180, 2004.

[71] J. Zhou, H. Ma, D. Zou, R. Tan, D. Wang, and R. Zheng, "Correlative factors of secondary fracture after percutaneous kyphoplasty for osteoporotic vertebral compression fracture," Zhongguo Xiu Fu Chong Jian Wai Ke Za Zhi, vol. 25, no. 10, pp. 1180-1183, 2011.

[72] Y.-J. Rho, W. J. Choe, and Y. I. Chun, "Risk factors predicting the new symptomatic vertebral compression fractures after percutaneous vertebroplasty or kyphoplasty," European Spine Journal, vol. 21, no. 5, pp. 905-911, 2012.

[73] P. Diel, L. Freiburghaus, C. Röder et al., "Safety, effectiveness and predictors for early reoperation in therapeutic and prophylactic vertebroplasty: short-term results of a prospective case series of patients with osteoporotic vertebral fractures," European Spine Journal, vol. 21, supplement 6, pp. S792-S799, 2012.

[74] H. Mao, J. Zou, D. Geng et al., "Osteoporotic vertebral fractures without compression: key factors of diagnosis and initial outcome of treatment with cement augmentation," Neuroradiology, vol. 54, no. 10, pp. 1137-1143, 2012.

[75] C. C. Matouk, T. Krings, K. G. Ter Brugge, and R. Smith, "Cement embolization of a segmental artery after percutaneous vertebroplasty: a potentially catastrophic vascular complication," Interventional Neuroradiology, vol. 18, no. 3, pp. 358-362, 2012.

[76] W. A. Sifuentes Giraldo, J. R. Lamua Riazuelo, J. I. Gallego Rivera, and M. Vazquez Diaz, "Cement pulmonary embolism after vertebroplasty," Reumatología Clínica, vol. 9, no. 4, pp. 239242, 2013.

[77] R. A. Llanos, A. Viana-Tejedor, H. R. Abella, and F. FernandezAviles, "Pulmonary and intracardiac cement embolism after a percutaneous vertebroplasty," Clinical Research in Cardiology, vol. 102, no. 5, pp. 395-397, 2013.

[78] A. Prokop, M. Hägele, U. Pfeilsticker, S. Koll, and M. Chmielnicki, "Pericardial perforation 2.5 years after kyphoplasty-a rare complication after cement extravasation," Unfallchirurg, vol. 116, no. 1, pp. 80-84, 2013.

[79] S. H. Lee, W. H. Kim, and J. K. Ko, "Multiple pulmonary cement embolism after percutaneous vertebroplasty," QJM, vol. 106, no. 9, pp. 877-878, 2013.

[80] F. J. Liu, H. Ren, Y. Shen, W. Y. Ding, and L. F. Wang, "Pulmonary embolism caused by cement leakage after percutaneous kyphoplasty: a case report," Orthopaedic Surgery, vol. 4, no. 4, pp. 263-265, 2012.

[81] I. Gosev, L. Nascimben, P. H. Huang et al., "Right ventricular perforation and pulmonary embolism with polymethylmethacrylate cement after percutaneous kyphoplasty," Circulation, vol. 127, no. 11, pp. 1251-1253, 2013.

[82] M. Bergmann, L. Oberkircher, C. Bliemel, T. M. Frangen, S. Ruchholtz, and A. Kruger, "Early clinical outcome and complications related to balloon kyphoplasty," Orthopedic Reviews, vol. 4, no. 2, article e25, 2012.
[83] P. Katonis, A. Hadjipavlou, X. Souvatzis, M. Tzermiadianos, K. Alpantaki, and J. W. Simmons, "Respiratory effects, hemodynamic changes and cement leakage during multilevel cement balloon kyphoplasty," European Spine Journal, vol. 21, no. 9, pp. 1860-1866, 2012.

[84] H. Abdelrahman, A. E. Siam, A. Shawky, A. Ezzati, and H. Boehm, "Infection after vertebroplasty or kyphoplasty. A series of nine cases and review of literature," The Spine Journal, vol. 13, no. 12, pp. 1809-1817, 2013.

[85] G. Lewis, "Injectable bone cements for use in vertebroplasty and kyphoplasty: state-of-the-art review," Journal of Biomedical Materials Research B, vol. 76, no. 2, pp. 456-468, 2006.

[86] T. A. Schildhauer, A. P. Bennett, T. M. Wright, J. M. Lane, and P. F. O'Leary, "Intravertebral body reconstruction with an injectable in situ-setting carbonated apatite: biomechanical evaluation of a minimally invasive technique," Journal of Orthopaedic Research, vol. 17, no. 1, pp. 67-72, 1999.

[87] A. Perry, A. Mahar, J. Massie, N. Arrieta, S. Garfin, and C. Kim, "Biomechanical evaluation of kyphoplasty with calcium sulfate cement in a cadaveric osteoporotic vertebral compression fracture model," Spine Journal, vol. 5, no. 5, pp. 489-493, 2005.

[88] M. A. K. Liebschner, W. S. Rosenberg, and T. M. Keaveny, "Effects of bone cement volume and distribution on vertebral stiffness after vertebroplasty," Spine, vol. 26, no. 14, pp. 1547$1554,2001$.

[89] S. Molloy, J. M. Mathis, and S. M. Belkoff, "The effect of vertebral body percentage fill on mechanical behavior during percutaneous vertebroplasty," Spine, vol. 28, no. 14, pp. 15491554, 2003.

[90] S. M. Belkoff, J. M. Mathis, L. E. Jasper, and H. Deramond, "The biomechanics of vertebroplasty: the effect of cement volume on mechanical behavior," Spine, vol. 26, no. 14, pp. 1537-1541, 2001.

[91] M. Rollinghoff, A. Hagel, J. Siewe et al., "Is height restoration possible with a comparatively smaller amount of cement in radiofrequency kyphoplasty using a monopedicle approach?" Zeitschrift für Orthopädie und Unfallchirurgie, vol. 151, no. 2, pp. 156-162, 2013.

[92] A. Kruger, G. Baroud, D. Noriega et al., "Height restoration and maintenance after treating unstable osteoporotic vertebral compression fractures by cement augmentation is dependent on the cement volume used," Clinical Biomechanics, vol. 28, no. 7, pp. 725-730, 2013.

[93] S. Brunton, B. Carmichael, D. Gold et al., "Vertebral compression fractures in primary care: recommendations from a consensus panel," Journal of Family Practice, vol. 54, no. 9, pp. 781-788, 2005.

[94] I. Papanastassiou, A. Filis, K. Aghayev, Z. Kokkalis, M. Gerochristou, and F. Vrionis, "Adverse prognostic factors and optimal intervention time for balloon kyphoplasty/vertebroplasty in osteoporotic fractures," BioMed Research International, vol. 2014, Article ID 925683, 7 pages, 2014.

[95] N. Suzuki, O. Ogikubo, and T. Hansson, “The prognosis for pain, disability, activities of daily living and quality of life after an acute osteoporotic vertebral body fracture: its relation to fracture level, type of fracture and grade of fracture deformation," European Spine Journal, vol. 18, no. 1, pp. 77-88, 2009.

[96] J. Steinmann, C. T. Tingey, G. Cruz, and Q. Dai, "Biomechanical comparison of unipedicular versus bipedicular kyphoplasty," Spine, vol. 30, no. 2, pp. 201-205, 2005.

[97] A. G. Tohmeh, J. M. Mathis, D. C. Fenton, A. M. Levine, and S. M. Belkoff, "Biomechanical efficacy of unipedicular versus 
bipedicular vertebroplasty for the management of osteoporotic compression fractures," Spine, vol. 24, no. 17, pp. 1772-1776, 1999.

[98] B. Chen, Y. Li, D. Xie, X. Yang, and Z. Zheng, "Comparison of unipedicular and bipedicular kyphoplasty on the stiffness and biomechanical balance of compression fractured vertebrae," European Spine Journal, vol. 20, no. 8, pp. 1272-1280, 2011.

[99] S.-B. Lee, K.-S. Cho, P.-W. Huh et al., "Clinical and radiographie results of unilateral transpedicular balloon kyphoplasty for the treatment of osteoporotic vertebral compression fractures," Acta Neurochirurgica, Supplementum, no. 101, pp. 157-160, 2008.

[100] A. K. Kim, M. E. Jensen, J. E. Dion, P. A. Schweickert, T. J. Kaufmann, and D. F. Kallmes, "Unilateral transpedicular percutaneous vertebroplasty: initial experience," Radiology, vol. 222, no. 3, pp. 737-741, 2002.

[101] W. S. Chang, S.-H. Lee, W. G. Choi, G. Choi, and B.-J. Jo, "Unipedicular vertebroplasty for osteoporotic compression fracture using an individualized needle insertion angle," Clinical Journal of Pain, vol. 23, no. 9, pp. 767-773, 2007.

[102] E. C. Papadopoulos, F. Edobor-Osula, M. J. Gardner, M. K. Shindle, and J. M. Lane, "Unipedicular balloon kyphoplasty for the treatment of osteoporotic vertebral compression fractures: early results," Journal of Spinal Disorders and Techniques, vol. 21, no. 8, pp. 589-596, 2008.

[103] C. Chen, H. Wei, W. Zhang et al., "Comparative study of kyphoplasty for chronic painful osteoporotic vertebral compression fractures via unipedicular versus bipedicular approach," Journal of Spinal Disorders and Techniques, vol. 24, no. 7, pp. E62-E65, 2011.

[104] Z. Wang, G. Wang, and H. Yang, "Comparison of unilateral versus bilateral balloon kyphoplasty for the treatment of osteoporotic vertebral compression fractures," Journal of Clinical Neuroscience, vol. 19, no. 5, pp. 723-726, 2012.

[105] B.-K. Song, J.-P. Eun, and Y.-M. Oh, "Clinical and radiological comparison of unipedicular versus bipedicular balloon kyphoplasty for the treatment of vertebral compression fractures," Osteoporosis International, vol. 20, no. 10, pp. 1717-1723, 2009.

[106] B. J. Rebolledo, B. P. Gladnick, A. Unnanuntana, J. T. Nguyen, C. K. Kepler, and J. M. Lane, "Comparison of unipedicular and bipedicular balloon kyphoplasty for the treatment of osteoporotic vertebral compression fractures: a prospective randomised study," The Bone \& Joint Journal, vol. 95, no. 3, pp. 401-406, 2013.

[107] H. J. Chung, K. J. Chung, H. S. Yoon, and I. H. Kwon, "Comparative study of balloon kyphoplasty with unilateral versus bilateral approach in osteoporotic vertebral compression fractures," International Orthopaedics, vol. 32, no. 6, pp. 817-820, 2008.

[108] I. Papanastassiou, M. Eleraky, R. Murtagh, Z. Kokkalis, M. Gerochristou, and F. Vrionis, "Comparison of unilateral vs bilateral kyphoplasty in multiple myeloma patients and the importance of pre-operative planning," Asian Spine Journal. In press.

[109] B. E. Dalton, A. C. Kohm, L. E. Miller, J. E. Block, and R. D. Poser, "Radiofrequency-targeted vertebral augmentation versus traditional balloon kyphoplasty: radiographic and morphologic outcomes of an ex vivo biomechanical pilot study," Journal of Clinical Interventions in Aging, vol. 7, pp. 525-531, 2012.

[110] P. Korovessis, K. Vardakastanis, T. Repantis, and V. Vitsas, "Balloon kyphoplasty versus KIVA vertebral augmentationcomparison of 2 techniques for osteoporotic vertebral body fractures: a prospective randomized study," Spine, vol. 38, no. 4, pp. 292-299, 2013. 

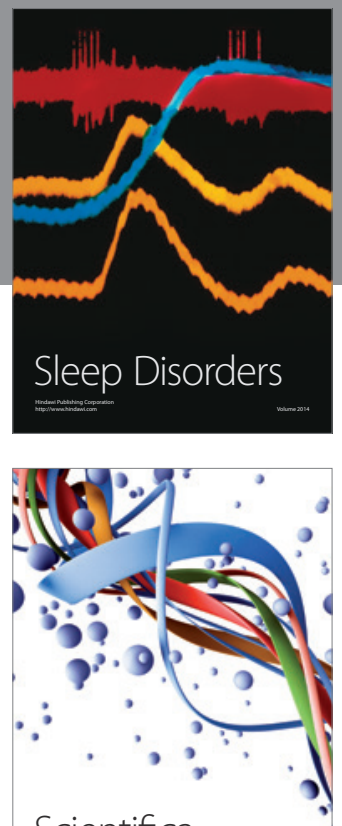

Scientifica
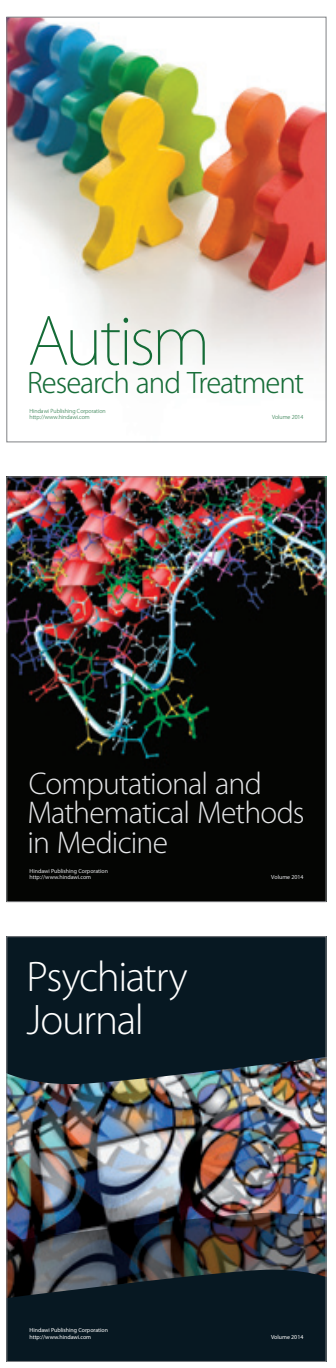
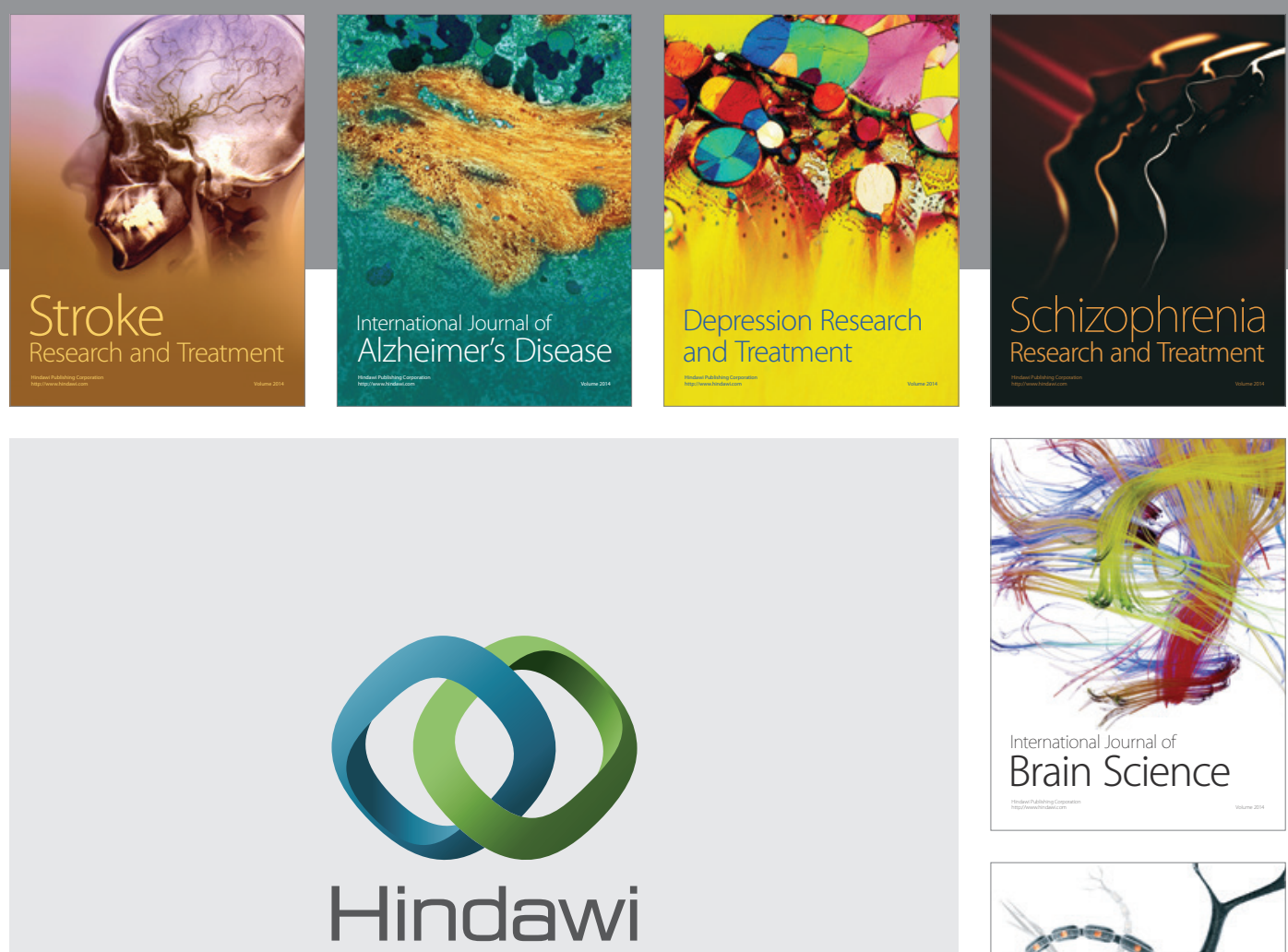

Submit your manuscripts at

http://www.hindawi.com
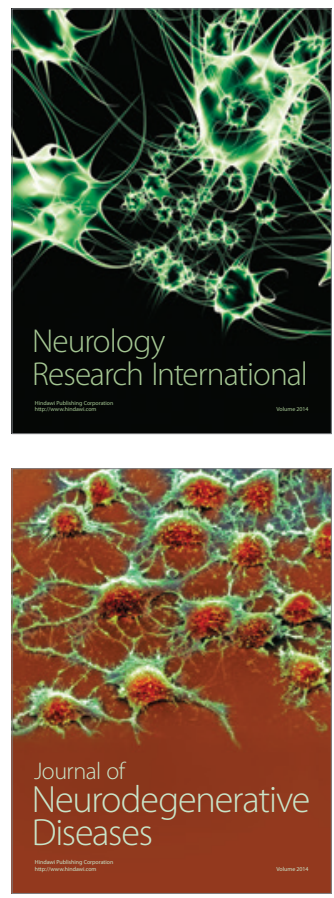

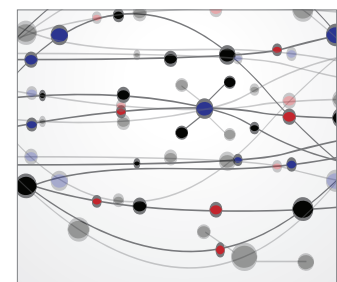

The Scientific World Journal
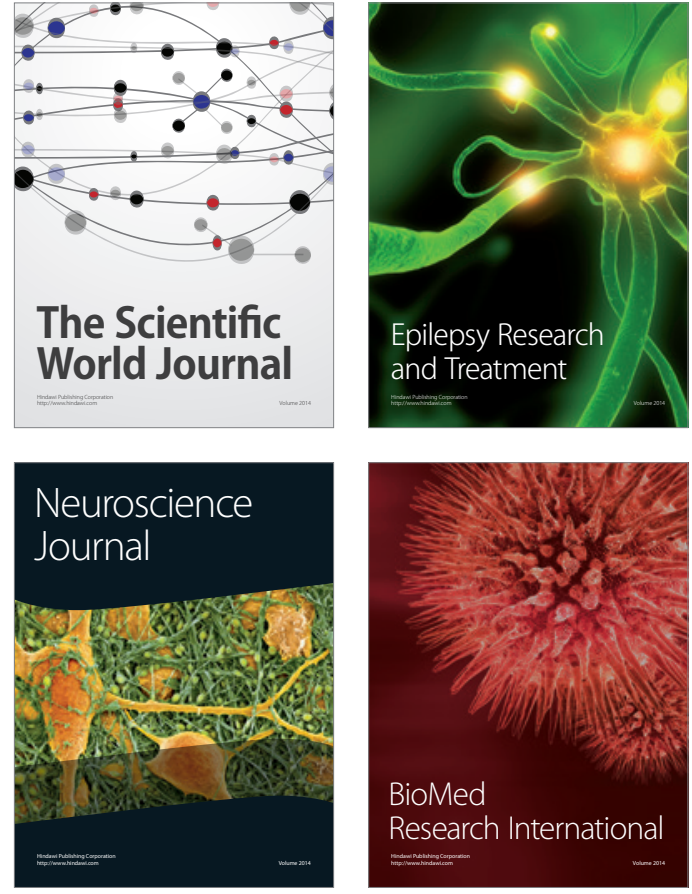

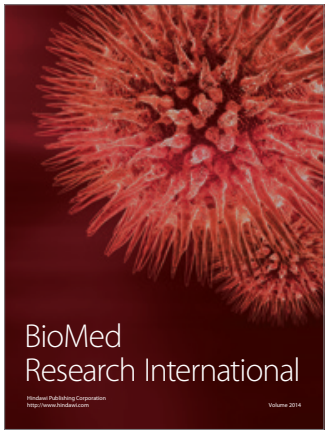

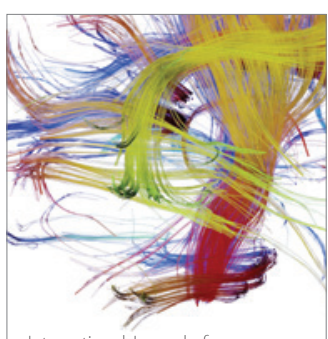

Brain Science

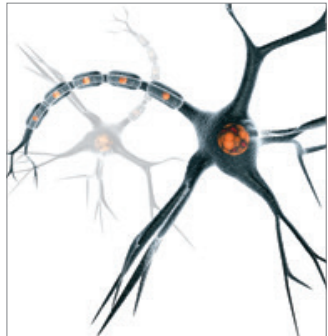

Neural Plasticity
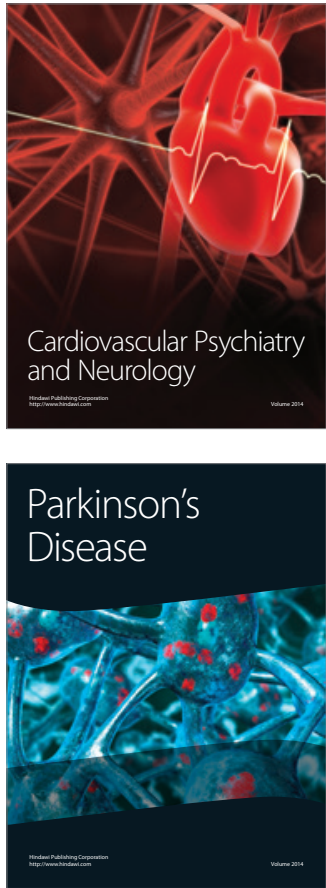